\section{International Scientific Journal Theoretical \& Applied Science}

p-ISSN: 2308-4944 (print)

e-ISSN: 2409-0085 (online)

Year: 2015

Issue: 10

Volume: 30

Published: $30.10 .2015 \quad$ http://T-Science.org

SECTION 2. Applied mathematics. Mathematical modeling.
Alexandr Shevtsov

candidate of technical sciences, member of PILA (USA), Department of «Mathematics», Deputy Director on Science of FITAT, Taraz state University named after M.Kh. Dulati,

Kazakhstan $\underline{\text { Shev_AlexXXXX@mail.ru }}$

Bakyt Turmakhanovich Bayeshov candidate of technical sciences, associate Professor, Taraz state University named after M.Kh. Dulati, Kazakhstan

\title{
ON ONE ALGORITHM FOR HOMOMORPHIC ENCRYPTION
}

Abstract: This paper discusses the implementation issues of homomorphic encryption algorithm in Delphi. The resulting algorithm allows to create a probability matrix of the ciphertext. The developed algorithm is efficient and test on the texts.

Key words: matrix, homomorphic encryption algorithm, encryption, delphi.

Language: English

Citation: Shevtsov AN, Bayeshov BT (2015) ON ONE ALGORITHM FOR HOMOMORPHIC ENCRYPTION. ISJ Theoretical \& Applied Science 10 (30): 1-3.

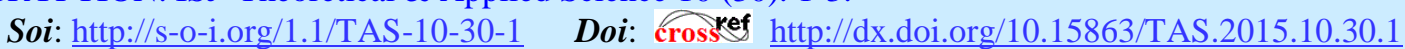

Homomorphic encryption is a form of encryption that allows you to perform mathematical operations with the ciphertext and obtain an encrypted result that matches the result of operations performed in plaintext. For example, one person could add two encrypted numbers and then another person could decrypt the result, without using any of them. Homomorphic encryption would allow to unite in one whole a variety of services, without providing data for each service. Distinguish partially homomorphic and fully homomorphic cryptosystem. While partially homomorphic system allows only one operation - addition or multiplication, a fully homomorphic cryptosystem supports the simultaneous execution of both operations, which allows holomorphe to compute arbitrary Boolean circuits. [1-8]

The basic steps in the encryption:

$$
A=\left(\begin{array}{cccccccc}
a_{11} & a_{12} & a_{13} & a_{14} & \ldots & a_{1 j} & \ldots & a_{1 n} \\
a_{21} & a_{22} & a_{23} & a_{24} & \ldots & a_{2 j} & \ldots & a_{2 n} \\
a_{31} & a_{32} & a_{33} & a_{34} & \ldots & a_{3 j} & \ldots & a_{3 n} \\
a_{41} & a_{42} & a_{43} & a_{44} & \ldots & a_{4 j} & . . & a_{4 n} \\
\ldots & \ldots & \ldots & \ldots & \ldots & \ldots & \ldots & \ldots \\
a_{i 1} & a_{i 2} & a_{i 3} & a_{i 4} & \ldots & a_{i j} & \ldots & \ldots \\
\ldots & \ldots & \ldots & \ldots & \ldots & \ldots & \ldots & \ldots \\
a_{m 1} & a_{m 2} & a_{m 3} & a_{m 4} & \ldots & \ldots & \ldots & a_{m n}
\end{array}\right) \quad V=\left(\begin{array}{c}
v_{1} \\
v_{2} \\
v_{3} \\
v_{4} \\
\ldots \\
v_{j} \\
\ldots \\
v_{n}
\end{array}\right)
$$

It is obvious that the homomorphism for works not executed. Because with the algorithm of encryption is partially homomorphic. Due to the fact that the algorithm is being built with private key,
- Imagine that we want to encrypt the number $\mathrm{x}$ (a small natural number).

- We will choose a random vector v (it will be our secret key).

- Possible to find a row of the matrix A that will be true $A_{i} v=x$, i.e., the multiplication of $\mathrm{A}$ on $\mathrm{v}$ will give the number $\mathrm{x}$.

- If we want to encrypt a new number $y$, then again you will find a row of the matrix $\mathrm{A}$, such that $A_{j} v=y$. Thus we can, with only one secret key $\mathrm{v}$, and encrypt any number of numbers where the code of each number is a string matrix.

- To decode the number, we multiply the matrix by the vector $\mathrm{v}$ secret. 


\begin{tabular}{|c|c|c|c|c|c|c|}
\hline Impact Factor: & $\begin{array}{l}\text { ISRA (India) } \\
\text { ISI (Dubai, UAE } \\
\text { GIF (Australia) } \\
\text { JIF }\end{array}$ & $\begin{array}{l}=1.344 \\
=0.829 \\
=0.356 \\
=1.500\end{array}$ & $\begin{array}{l}\text { SIS (USA) } \\
\text { PИHЦ (Russia) } \\
\text { ESJI (KZ) } \\
\text { SJIF (Morocco) }\end{array}$ & $\begin{array}{l}=0.912 \\
=0.179 \\
=1.042 \\
=2.031\end{array}$ & ICV (Poland) & $=6.630$ \\
\hline
\end{tabular}

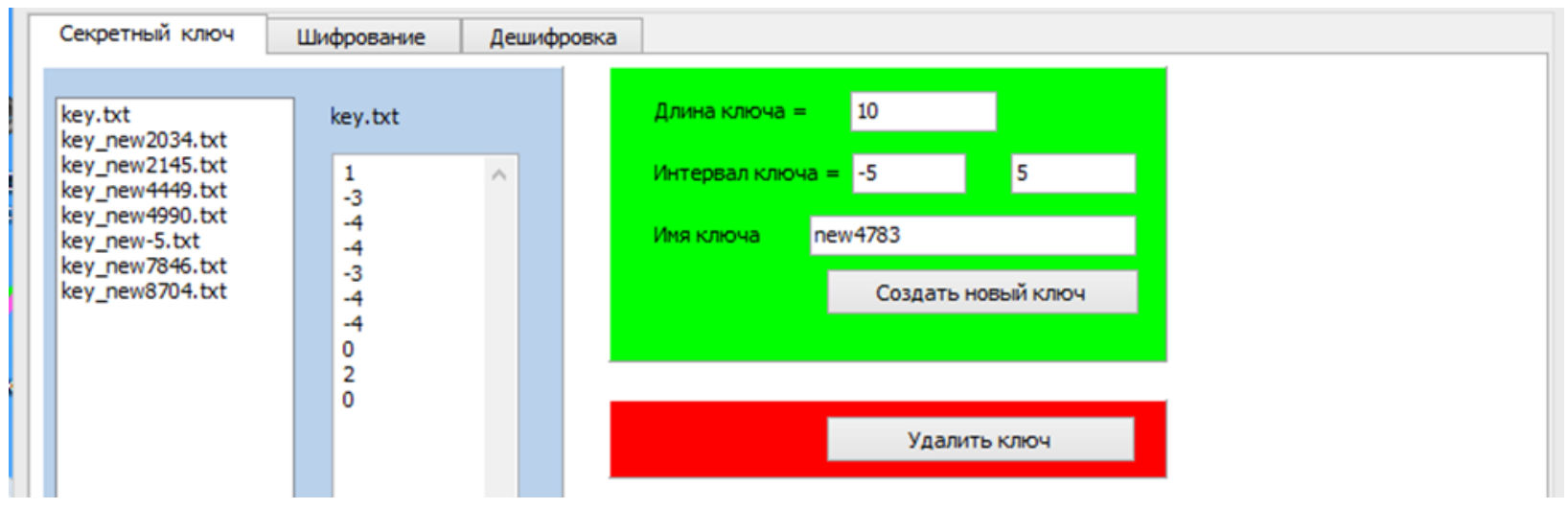

Figure 1 - Creating a secret key.

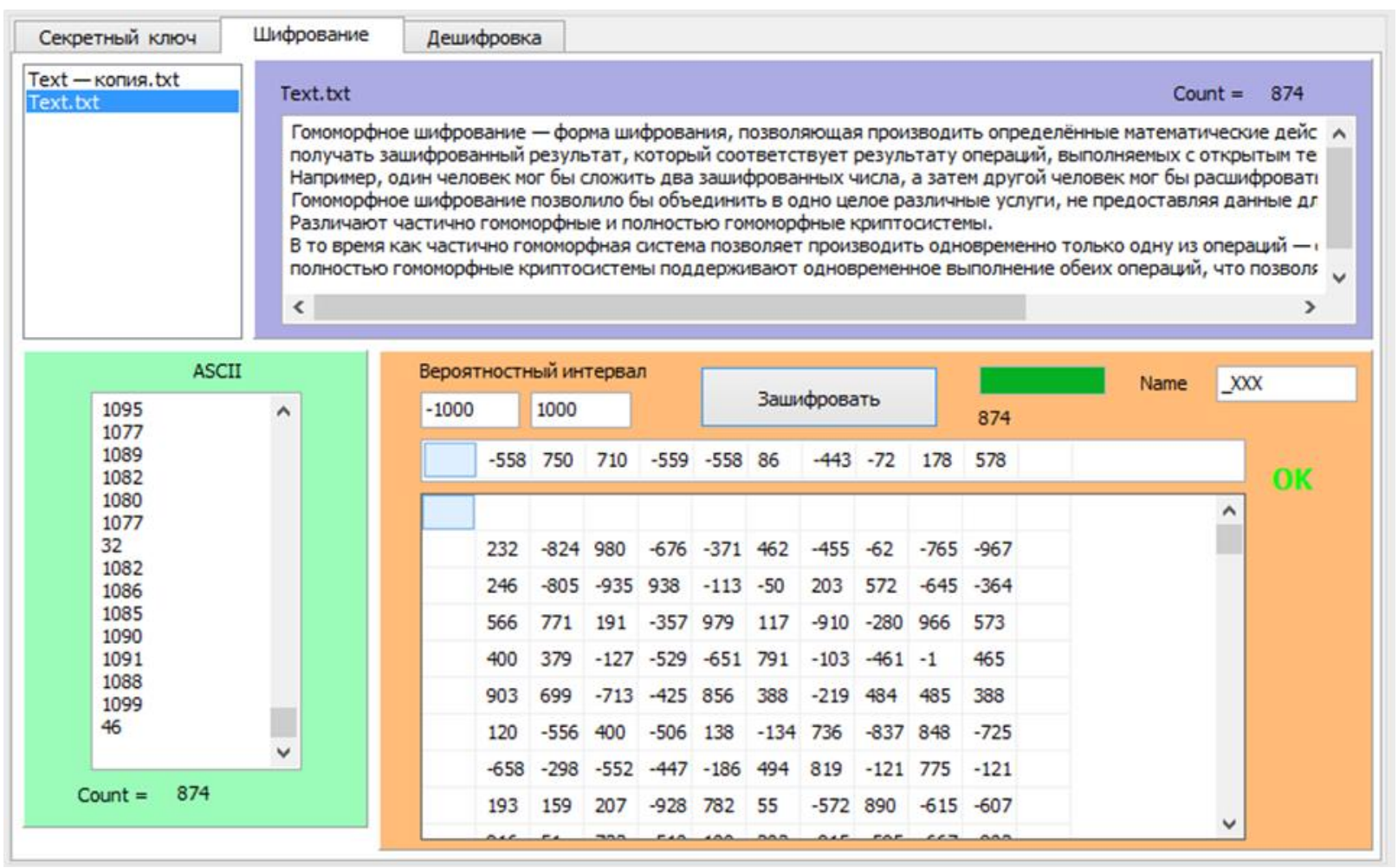

Figure 2 - Enter the source text. The transformation of the original text according to the ASCII table and encrypted text in the matrix.

\section{Conclusion}

As a result of the studied encryption algorithms based on the homomorphic properties and the conducted research we can draw the following conclusions:

- The existing encryption algorithms are not perfect, fully homomorphic encryption algorithm is still not created.
- Our proposed algorithm encryption has homomorphic properties of probabilistic addition of encrypted matrices.

- The proposed algorithm is implemented and aprobirovany on a computer in Delphi environment.

- When increasing the length of the secret key, the cryptographic strength is increased more than the increase in the probability interval.

ISPC Innovations in science, 


\begin{tabular}{|c|c|c|c|c|c|c|}
\hline Impact Factor: & $\begin{array}{l}\text { ISRA (India) } \\
\text { ISI (Dubai, UAE } \\
\text { GIF (Australia) } \\
\text { JIF }\end{array}$ & $\begin{array}{l}=1.344 \\
=0.829 \\
=0.356 \\
=1.500\end{array}$ & $\begin{array}{l}\text { SIS (USA) } \\
\text { PИНЦ (Russia) } \\
\text { ESJI (KZ) } \\
\text { SJIF (Morocco) }\end{array}$ & $\begin{array}{l}=0.912 \\
=0.179 \\
=1.042 \\
=\mathbf{2 . 0 3 1}\end{array}$ & ICV (Poland) & $=6.630$ \\
\hline
\end{tabular}

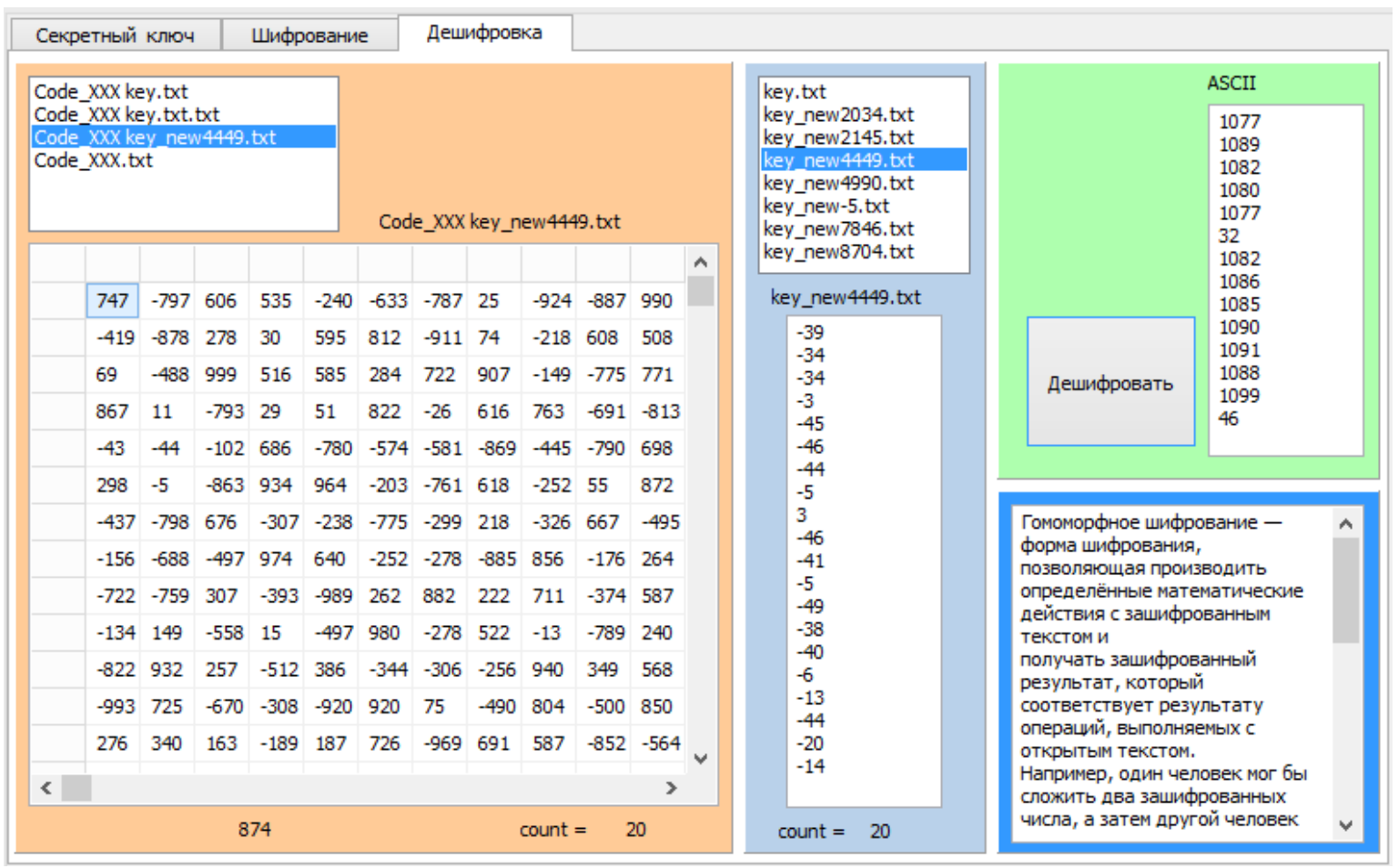

Figure 3 - Decoding of the source text using the correct key.

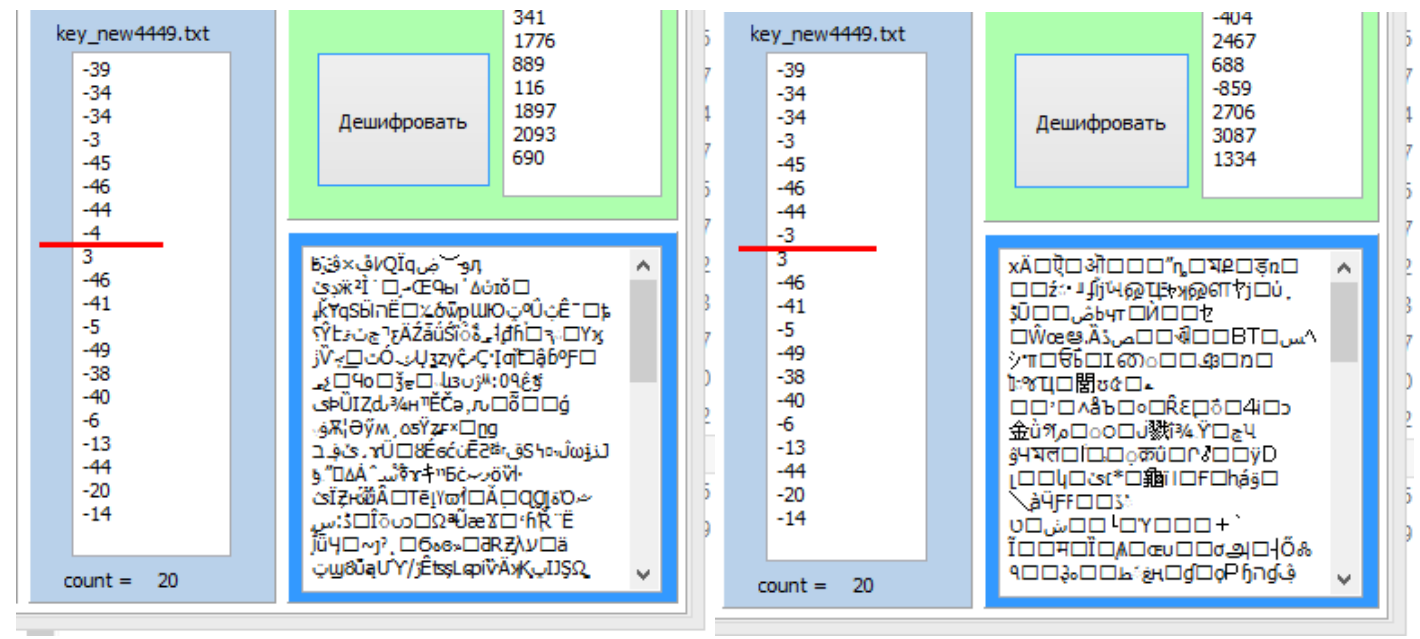

Figure 4 - Error decoding data when the error in the secret key.

\section{References:}

1. Burris SN, Senkeppenever KP (1981) Kurs v Universal'noy algebre. Springer-Verleg.

2. Kokorin AI (1972) Lineyno uporyadochennye gruppy: monografiya.- M.: Nauka,1972.-199 p.

3. Kopytov VM, Mamaev II (1968) Absolyutnaya vypuklost' nekotorykh podgrupp uporyadochivaemoy gruppy. Algebra i logika. Novosibirsk, 1968.-T.7.-№2.-pp.20-26.

4. Menezes AJ, Oorschot PS, Vanstone SA (2015) The ElGamal signature scheme // Handbook of applied cryptography.

5. Venbo Mao (2005) Sovremennaya Kriptografiya. Teoriya i Praktika. - Spb.: Vil'yams, 2005.
6. (2015) Kriptograficheskie algoritmy. Available: http://www.codenet.ru/progr/alg/crypt.php (Accessed: 20.10.2015).

7. (2015) Zadachi kriptografii. Ponyatie stoykosti kriptograficheskogo algoritma. Available: http://allrefs.net/c39/38j2b/ (Accessed: 20.10.2015).

8. Nil's Fergyuson, Bryus Shnayer (2004) Prakticheskaya kriptografiya $=$ Practical Cryptography: Designing and Implementing Secure Cryptographic Systems. - Moscow: Dialektika, 2004. - 432 p. 